\title{
DIEZMOS Y CONFLICTOS EN EL MARQUESADO DE LOS VÉLEZ (SIGLO XVI)
}

\author{
Antonio Luis Cortés Peña \\ Universidad de Granada
}

\section{$\underline{\text { RESUMEN }}$}

La compleja y diversa estructura de la percepción y distribución de los diezmos en el reino de Granada como consecuencia de su conquista por los Reyes Católicos y, como consecuencia, por la obtención para su Iglesia del Regio Patronato, es la base de este artículo, particularmente centrado en las peculiaridades almerienses, causantes de sucesivos conflictos entre la jerarquía eclesiástica y los señores temporales; a modo de ejemplo se analizan dos de estos hechos conflictivos.

Palabras claves: Edad Moderna, Iglesia, Reino de Granada, Diezmos, Señoríos

\section{$\underline{A B S T R A C T}$}

The complex and diverse structure of the perception and distribution of the "diezmos" in the kingdom of Granada as a result of its conquest by Kings Católicos and, like consequence, by the obtaining for its Church of the Regal Patronage, is the base of this article, particularly centered in the peculiarities of Almeria, the temporary causes of successive conflicts between the ecclesiastical hierarchy and gentlomen; as a example two of these conflicting facts are analyzed.

Keywords: Modern Age, Church, Kingden of Granada, Social's Conflicto.

Siguiendo antecedentes medievales, pero a través de vías en gran parte nuevas, durante la época moderna la imbricación entre la Iglesia y el Estado fue una constante en el proceso evolutivo sufrido por la Monarqula española; la estrecha unión entre el poder civil y el religioso iba a estar presente en la política seguida por los soberanos hispánicos desde los primeros momentos de la configuración 
de la Monarquía gracias a la labor de los Reyes Católicos, quienes, para su conflictiva entronización, tanto apoyo eclesiástico recibieron, en particular desde amplios sectores de la lglesia castellana, lo que, sin embargo, no impidió la existencia de duros enfrentamientos tanto a niveles internos como, sobre todo, en sus relaciones con Roma ${ }^{1}$, circunstancia que se iba a prolongar asimismo a lo largo de los siglos modernos. No cabe duda que este

uíntimo enlace entre el trono y el altar, remachado en el Reino de Granada gracias al derecho de parronazgo, se manifiesta en el reparto de los diezmos. La Corona resulta beneficiaria de una buena parte, de la que va a hacer participe a la nobleza para complementar sus rencasn².

Es decir, la política eclesiástica de los Reyes, encaminada a un control más efectivo sobre la Iglesia de nuevo cuño que se instaura en el territorio del antiguo reino nazarí gracias a la obtención de las bulas de mayo y julio de 1486, culminadas por la Ortodoxae fidei de 13 de diciembre de ese mismo año, todas ellas otorgadas por Inocencio VIII, pone las iglesias del reino de Granada bajo el especial régimen de Real Patronato. Al margen de otras consideraciones en diferentes ámbitos, la situación económica, que posteriormente iba a ser encausada a través de normas muy variadas, concedía a la Corona evidentes privilegios, aunque, en gran medida, tenía como contrapartida echar sobre sus espaldas el sostén económico de las diócesis creadas en las tierras granadinas. Tanto la Iglesia como la Corona se encontraban, por tanto, con la necesidad de atender a una organización eclesiástica que en los aspectos económicos presentaba circunstancias bien distintas, en su conjunto, de las existentes en el resto de los dominios de los soberanos Trastámara -lo mismo sucedería con Puerto Real, las Canarias y, de inmediato, las Indias-. Es probable que la complejidad provocada por la estructuración del nuevo sistema haya sido la causa -a la que se suman los problemas derivados de la conservación y consulta de no pocos archivos- de que en la actualidad aún tengamos lagunas y datos contradictorios que afectan a un conocimiento adecua-

${ }^{1}$ CORTÉS PEÑA, Antonio Luis, «A propósito de la Iglesia y la conquista del reino de Granada», en el vol. misceláneo Iglesia y Cuitura en la Andahicio Moderna. Tendencias de la investigación, estado de las cuestiones. Granada, Proyecto Sur, 1995. Especialmente las pp. 141-148.

2 BENÍTEZ SÁNCHEZ-BLANCO, Rafael, «El diezmo de moriscos en el obispado de Málaga», Estudis, 4 (1975), p. 173. 
do de los diezmos en la mayor parte de las diócesis granadinas ${ }^{3}$, de ahí que, antes de referirme al conflicto concreto que enfrentó a los marqueses de los Vélez con el obispado de Almería, sea necesario dibujar un panorama sobre la distribución de los diezmos en el ámbito general del reino de Granada y, de forma particular, exponer algunas peculiaridades del caso almeriense. Necesariamente ha de ser

\footnotetext{
${ }^{3}$ Para aquellos interesados en el terna parece conveniente citar la bibliografia más representativa al respecto: BENÍTEZ SÁNCHEZ-BLANCO, Rafael, «El diezmo de los moriscos en el obispado de Málaga), Estudis, 4 (1975), pp. 162-177. CABRILLANA, Nicolás, Almeria morisca. Granada, Universidad, 1982. CAMPOS ROJAS, M. Victoria, "Introducción al estudio de los diezmos bajo el reinado de los Reyes Católicos), Jábega, 19 (1977), pp. 23-27. ESPINAR MORENO, M. y FERNÁNDEZ ORTEGA, A., «Erección de la iglesia catedral de Almería y de las de su obispado por los Reyes Católicos (1492-1514)», Roel, 12 (1992/93), pp. 21-77. FRANCO SILVA, Alfonso, «Datos demográficos y organización municipal de las villas almerienses de los Vélez (1492-1540)», Gades, 5 (1980), pp. 97-111; - «El obispado de Almería tras su incorporación a la Corona de Castilla», Cuadernos de Estudios Medievales, VI-VII (1978-1979), pp. 79-95; -, «El señorio de los Vélez entre 1492 y 1540. Población y concejos», Revista Velezana, 12 (1993), pp. 5-12; -, «La formación del señorío de los Vélez. Sus rentas y propiedades (1492-1540)», en Actas del I Coloquio de Historia de Andalucia. Andalucía medieval. Córdoba, Caja de Ahorros, 1982. GARRIDO ARANDA, Antonio, Organización de la Iglesia en el Reino de Granada y su proyección en Indias. Siglo XVY. Sevilla, Escuela de Estudios Hispanoamericanos/Universidad de Córdoba, 1980. GARRIDO GARCÍA, C.J,, «El sistema decimal en la diócesis de Guadix según un memorial administrativo de 1642», en El reino de Granada en el siglo XVII. Actas de las jornadas celebradas del 9 al 11 de octubre de 1997. Almeria, Diputación Provincial, 2001. GARZÓN PAREJA, Manuel, Diezmos y tributos del clero de Granada. Granada, Archivo de la Real Chancillería, 1974. GÓMEZ LORENTE, Manuel, «Los diezmos de los cristianos viejos en el Scinorío de los Vélez. El caso de Vélez-Rubio», Revista Velezana, 4 (1987), pp. 91-99. GRIMA CERVANTES, Juan, «Las capitulaciones pactadas en 1488 y 1501 ertre los Reyes Católicos y los mudéjares de Vélez-Blanco y Vélez-Rubion, Revista Velezana, 6 (1987), pp. 75-85. LÓPEZ ANDRÉS, Jesús María, «Erección parroquial en la diócesis almeriense: cuestiones de límites y jurisdicciones (1492-1509)", en Comitnicaciones presentadas al LX Congreso de ProfesoresInvestigadores. Málaga, Hespérides, 1991, pp. 491-502; -, "Iglesia y Estado Moderno: La ordenación de la diócesis dè Almería en época de los Reyes Católicos», en el vol. colectivo Almería entre culturas (siglos XII1-XVI). Almería, Diputación Provincial, 1990, 1, pp. 317-331; -, «Las rentas decimales del obispado de Almería a finales del siglo XV y comienzos del XVI; sı valoración como eje económico en la formación de la Iglesia de Estadon, Anuario de Investigaciones Hespérides, 1 (1994), pp. 217-228. MARÍN LÓPEZ, Rafael, «La Iglesia y el encuadramiento religioso», en Rafael G. Peinado Santaella (ed.), Historia del Reino de Granada. 1. De los orlgenes a la época mudejar (hasta 1502). Granada, Universidad/El Legado Andalusí, 2000, pp. 661-686; MARTÍNEZ MEDINA, Francisco Javier, «La Iglesia», en M. Barrios Aguilera (ed.), Historia del Reino de Granada. Il. La época morisca y la repoblación (1502-1630). Granada, Universidad/El Legado Andalusí, 2000, pp. 251-307. PÉREZ BOYERO, Enrique, «La construcción de las iglesias en el marquesado de los Vélez», en Actas del VI Simposio Internacional de Mudejarismo. Teruel, Dipulación Provincial, 1995, pp. 811-831; ---, Moriscos y cristianos en los señorios del reino de Granada (1490-1568). Granada, Universidad, 1997. RIESCO TERRERO, Ángel, "Restauración de la sede de Málaga y de la vida parroquial y monástica en el reino de Granada. Postura del Papa Inocencio VIIl y política de los Reyes Católicos», en J.E. López de Coca Castañer (ed.), Estudios sobre Málaga y el Reino de Granada en el $V$ Centenario de la conquista. Málaga, Diputación Provincial, [9987, pp. 383-399. SORIA MESA, Enrique, Seríores y oligarcas. Granada, Universidad, 1997. SUBERBIOLA MARTÍNEZ, Jesús, «Físco, franquicias y problemas en la repoblación de Málaga (siglos XV-XVI)», Cuadernos de Estudios Medievales, II-III (1974-1975); - Real Patronato de Granada. El atzobispo Talavera, la lglesia y el estado Moderno. Granada, Caja de Ahorros, 1985. SZMOLKA CLARES, José, «El Regio Patronato y la nueva Iglesia de Granada», XX Siglos, 10 (1992), pp. 85-91.
} 
escueto, pero todo lo preciso que sea posible tratando de esclarecer las contradicciones existentes en la bibliografía al respecto.

En primer lugar, resulta imprescindible hacer mención a la dualidad poblacional que existió en el reino recién conquistado, dualidad que oficialmente perduraria hasta comienzos del siglo XVI; los diecisiete años transcurridos entre 1485, fecha de la conquista e incorporación a Castilla de importantes núcleos de población musulmana del occidente malagueño, y 1502, año en que legalmente, tras la conversión forzosa, no quedan practicantes del Islam en tierras granadinas, fueron testigos de la coexistencia de una sociedad dual-formada por cristianos y musulmanes (los judíos habían sido expulsados en el mismo 1492)-que, a pesar de tener amplios precedentes en otros territorios peninsulares reconquistados con anterioridad, "puesto que el mudejarismo granadino se modela sobre los viejos patrones medievales, largamente ensayados desde la conquista de Toledo a fines del siglo XI"4, presenta claras diferencias con los casos anteriores. Entre las mismas destaca el hecho de que, en esta ocasión, tanto el poder real ${ }^{5}$ como las autoridades eclesiásticas mucstran especial interés, a pesar de lo estipulado en las capitulaciones, de terminar cuanto antes con esta doble confesionalidad de los súbditos, lo que tratan de lograr mediante el apoyo a un proceso de castellanización/cristianización de los vencidos, realizado bien a través de métodos de persuasión pacífica - Talavera-, bien mediante la exigencia perentoria de la intransigencia -Cisneros-. Parece fuera de duda que esta actitud uniformizadora estaba movida por factores muy diversos, entre los que el nuevo talante sociomental que se extendía por Europa, así como las circunstancias políticas internacionales propiciadas por el avance otomano en el Mediterráneo, debieron de influir de modo determinante; no obstante, debió de resultar decisivo, como ha escrito el profesor Galán Sánchez, "el desequilibrio inicial entre el número de los cristianos y el de los musulmanes que conforma el reino como lo que he denominado en otro lugar «una inmensa morería»", ya que, al margen de consideraciones religiosas, semejante situación era contemplada por los vencedores como un grave peligro en potencia que podía manifestar su realidad en cualquier momento.

Pienso, en cuanto al tema que aquí nos ocupa, que esos difíciles y tensionados años de obligada coexistencia entre cristianos viejos y mudéjares fueron decisivos para la complejidad alcanzada en estos territorios a la hora del esta-

\footnotetext{
${ }^{4}$ GALÁN SÁNCHEZ, Ángel, "Los vencidos: exilio, integración y resistencia», en Rafael G. Peinado Santaella (ed.), Historia del Reino de Granada. I. De los origenes a la época mudéjar (hasta I502). Granada, Universidad/E1 Legaco Andalusí, 2000, p. 527.

"No así, los poderes señoriales, quienes, como es sabido, se convierten en protectores de la población vencida, no precisamente por altruismo, sino en defensa de sus propios intereses rentistas.

${ }^{5}$ GALÁN SÁNCHEZ, A., «Los vencidos: exilio..., pp. 527-528.
} 
blecimiento de los diezmos, pues, si en un principio lógicamente hubo de reflejarse la citada dualidad, con posterioridad, a partir de 1502 , convertidos definitivamente los mudéjares en cristianos nuevos, moriscos, y, por tanto, desaparecida desde el punto de vista oficial la dualidad, en este aspecto, al igual que en otros, no se llegó a la igualdad legal y persistirían las diferencias. Entre otros motivos, y con respecto al diezmo, porque tratar a los recién convertidos de modo similar a los cristianos viejos suponía un apreciable descenso en los ingresos percibidos por los monarcas y, en su caso, por los señores temporales. Pero, vayamos por partes.

Desde un primer momento, los mudéjares granadinos habían conseguido el mantenimiento del sistema fiscal nazarí, lo que no dejó de crear problemas muy diversos para el fisco castellano, dado el desconocimiento que se tenía del complejo sistema tributario existente antes de la conquista. Sin embargo, una de las pechas conocidas más importantes, el diezmo7, se convertía en pieza clave del nuevo sistema impositivo, por lo que los Reyes Católicos, con el fín de evitar posibles ambigüedades, logran de Inocencio VIII, antes de finalizar la guerra (1487), una bula, la Dum indefesse solicitudinis, en la que se les otorga tanto a ellos como a sus sucesores dicha imposición, que pasa a conocerse como el diezmo mudéjar. "El mismo Papa les concederá también las tercias [de los cristianos viejos] de los lugares reconquistados y por reconquistar del reino nazari. Mercedes que serán ratificadas por otra bula del mismo Papa el 20 de mayo de $1488^{\prime \prime}$.

De este modo, hasta la rebelión mudéjar de 1500 , el panorama, aunque dispar, queda claro y bien reflejado en la distribución que se contempla en la erección catedralicia hecha por el cardenal don Pedro González de Mendoza en $1492^{9}$.

\footnotetext{
${ }^{7}$ La presión físcal nazarí era superior a la de Castilla; uno de sus múltiples impuestus era el diezmo, no exactamente igual que el castellano. " $\mathrm{E} 1$ fruto de las cosechas se gravaba con una cuantía del 10 por ciento en el caso de los cereales, legumbres, miel y cera o el 2,5 por ciento si estamos refiriéndonos a viñas y árboles frutales («alacer»). Esta última cantidad se aplicaba al valor apreciado de los bienes raíces agrícolas (《almaguana»). El cobro de este grupo, con más o menos variantes estaba generalizado en todo el reino". lbidem, p. 548.

${ }^{8}$ GÓMEZ LORENTE, M., «Los diezmos de los cristianos viejos..., p. 91 ,

- "En el mismo momento que se fundó la catedral de Granada, 21 de mayo de 1492, don Pedro González de Mendoza instituía las Almería, Guadix y Mălaga, con la misma organización teórica que la metropolitana de las que se constituyen en sufragáneas. Sin embargo, Málaga en realidad pasó a la jurisdicción de Sevilla, a donde había pertenecido en época goda". GARRIDO ARANDA, A., Organización de la Iglesia..., p. 62.
} 
Los diezmos de los cristianos viejos ${ }^{10}$ se reparten de este modo: $2 / 9$, las tercias, para la Corona, y $7 / 9$ para la Iglesia ${ }^{11}$; mientras que el diezmo mudéjar era recibido en su integridad, al margen de posibles cesiones voluntarias, por la Corona y los señores temporales. Esta situación determina que hasta 1501, los rendimientos decimales para la Iglesia del reino granadino, dado el bajo contingente poblacional de cristianos viejos, sean muy escasos, y, por tanto, que tenga la necesidad de vivir "prácticamente de la dotación real"'2.

El nuevo status mudéjar, tras el fracaso de la rebelión, las nuevas capitulaciones y, finalmente, la promulgación de la Real Cédula que decretaba "la expulsión o la conversión" (12 de febrero de 1502), vino a cambiar estas condiciones. Antes de esa fecha, habían sido muchos los granadinos musulmanes que, para evitar las represalias por la participación en la revuelta, habían optado por abrazar el cristianismo, por ello, los Reyes Católicos para tratar de paliar el previsible quebranto económico para su hacienda, consiguieron que Alejandro VI promulgase una bula, Cum ad illos fidei, con fecha 5 de junio de 1500 , en las que se les concedía las dos terceras partes -seis novenos- de los diezmos de los cristianos nuevos, con el deber de edificar las iglesias, a las que se dejaba la otra tercera parte -tres novenos-; la evidente disminución de ingresos que, a pesar de la concesión, suponía la medida hizo que los monarcas hispanos aún insistiesen ante la Santa Sede hasta lograr una nueva bula, la Eximiae devotionis, -15 de julio de 1501-, mediante la que se les otorgaba la totalidad de dichos diezmos, aunque con la obligación de atender económicamente a las iglesias. Por distintas razones, entre las que pueden destacarse la oposición mostrada por el clero, esta bula nunca se puso en práctica, por lo que, otra nueva, Ad apostolicae dignitatis, pro-

\footnotetext{
11. Lógicamente, la debilidad de los mismos, durante los primeros ar̃os siguientes a la conquista, eran patente dado que la llegada y establecimiento de pobladores cristianos se producía con cierta lentitud, to que suponia que no fucran nada despreciables las subvenciones concedidas por los monarcas para el sostenimiento de la Iglesia granadina. De ahí que no sen descabellado contestar afirmativamente a la pregunta hecha en su día por el profesor Marin: "¿Se puede por ello deducir que los reyes esperaban que pronto los musulmanes se marcharian o se convertirian, dando así a las capitulaciones un carácter transitorio motivado, en el caso concreto de Granada, por la necesidad de acabar una larga guerra?". MARÍN LÓPEZ, Rafael, El Cabildo de la Catedral de Granada en el siglo XVI. Granada, Universidad de Granada, 1988, p. 327. Unas palabras de don Pedro González de Mendoza expresadas en el mismo documento fundacional de la lglesia metropolitana no pueden ser más elocuentes en este sentido: $\mathbb{k}[\ldots]$ cuando sea Dios servido que las dichas mezquitas se consagren en iglesias [...]». Erección de la Igiesia metropolitana de Granada... Granada, 1803, p. 14.

"La distribución de los diezmos pertenecientes a la Iglesia de Almeria, la que aquí nos interesa, se distribuyen, según el documento de erección: "Para el obispo, la cuarta parte (1/4) de todos los diezmos. Para los clérigos beneficiados, la cuarta parte de todos los diezmos que correspondar a su iglesia, sacando la décima (1/10) de esta parte para el sactistán. Para los Reyes, sus tercias (2/9 del total). De lo que quede, - un tercio, para la Fábrica - un tercio, para Mesa Capitular - un tercio, para hospital $u$ hospitales del mismo territorio, menos la décima (1/10) que se sacará para mantener el Hospital Mayor de la ciudad de Almeria", GÓMEZ RUIZ, Trino, El Hospital Real de Santa Maria Magdalena y la Casa de Expósitos de Almería. Almería, Diputación Provincial, 1997, p. 29.

${ }^{12}$ MARÍN LÓPEZ, R., Op. cit., p. 332.
} 
mulgada meses más tarde, el 22 de noviembre de 1501, venía a dejar las cosas como se había establecido en la del año anterior, especificando que el tercio correspondiente a la Iglesia "quedaba para dotación de las parroquias y sustento de los beneficiados y sacristanes, siendo excluidos de esta distribución los obispos, los cabildos catedralicios y hospitales de las cuatro diócesis del reino"13, poco antes, el 14 de octubre, una disposición de los Reyes Católicos había dotado "las futuras parroquias del arzobispado con los bienes pertenecientes a las antiguas mezquitas ahora transformadas en templos cristianos ${ }^{14}$.

Muy pronto esta distribución de los diezmos fue cuestionada por la jerarquía eclesiástica, reclamando una mayor participación en las cantidades recaudadas. Así, a nivel ya de cada diócesis, los obispos y los cabildos comenzaron a pedir un cambio en la situación establecida por considerarla discriminatoria hacia ellos. A este espíritu responde el nuevo reparto que en la diócesis malagueña realiza su segundo obispo, Diego Ramírez de Villaescusa, el 18 de enero de 1510, gracias a un breve de Julio II, conseguido el 4 de mayo del año anterior; la modificación introducida no afectaba a los pueblos habitados por cristianos viejos, "pero en los de moriscos - «aquellos lugares en que el real fisco o algún señor temporal percibe más de dos novenas partes 》- atribuye a la mesa episcopal la cuarta parte de todos los diezmos, a la Corona y señores su parte, y el resto a repartir entre beneficiados y fábrica"15. El perjuicio para estos últimos era evidente, lo que desembocaría en el inicio de un largo contencioso al respecto. No quedó así la cosa, pues las insistentes lamentaciones de obispo y cabildo lograron de inmediato, el 23 de marzo de 1510, que la Corona -no así los señores, origen, por ello, de inmediatos litigios- cediese una parte de sus ingresos, quedando reducida su percepción a 3/9; aún más, la porfía de la jerarquía malagueña obtuvo, el 20 de octubre de $1511,1 / 9$ más de la parte correspondiente a la Corona, quedando ésta con los $2 / 9$, "es decir, las famosas tercias tradicionales, tanto en las poblaciones de cristianos viejos como nuevos". Este hecho, unido a otras concesiones logradas en estas fechas por los señores temporales malagueños, ha llevado a defender al profesor Suberbiola que en estos años se asiste a una regresión en la formación del Estado Moderno, pues "de este modo se ponía en entredicho toda la política anterior, hallándonos en una fase de franca transición, en la cual la correlación de fuerzas, al menos en el Reino de Granada, se estaba alterando profundamente en favor del feudalismo laico y eclesiástico"sts.

\footnotetext{
1. PÉREZ BOYERO, E., «La construcción de las..., p. 812.

i4 SUBERBIOLA MARTÍNEZ, J., Real Patronato de Granada.., p. 218.

${ }^{19}$ BENÍTEZ SÁNCHEZ-BLANCO, R., kEl diezmo de moriscos..., p. 167. Esta nueva distribución originaria un largo pleito entre obispo, cabildo y beneficindos, que aún segui ría cuando estalló la rebelión morisca de 1568.

${ }^{16}$ SUBERBIOLA MARTÍNeZ, J., Real Patronato de Granada..,, pp. 304-305.
} 
Se acepten, se maticen o se nieguen estos planteamientos, lo que resulta incontestable es que la Corona cede una parte importante de la recaudación que en un principio recibía de los diezmos, aunque bien es verdad que eso hacía más liviana la carga económica que debia de soportar, debido a su patronazgo, para el sostenimiento de la Iglesia de los territorios del reino granadino.

¿Mas, qué ocurría en la diócesis de Almería en esas mismas fechas?

Dado que las posturas sostenidas por la Corona y por los señores temporales ante las reclamaciones de la jerarquía eclesiástica por la distribución de los diezmos eran bien diferentes en todos los territorios de las diócesis instauradas en el reino granadino, para mejor comprender las peculiaridades almerienses es necesario tener presente el peso que los señoríos tenían dentro del territorio de su jurisdicción eclesiástica, "baste señalar que de los 101 pueblos que actualmente componen la actual provincia de Almería, 52 eran de señorío"17, hecho diferencial que condujo al obispo, fray Diego Hernández de Villalán a sostener múltiples, largos y costosos pleitos con todos los señores temporales de su diócesis, tanto por la cuestión de los diezmos como por la construcción de los templos parroquiales y por la misma organización eclesiástica de cada uno de los señoríos, ya que los señores desarrollaron una política caracterizada por un severo control político y económico de la Iglesia en sus tierras jurisdiccionales.

Hemos de tener en cuenta que, salvo excepciones, la mayor parte de los habitantes de las tierras almerienses de señorío eran moriscos, de ahí que "los conflictos entre la Iglesia y los señores se planteen generalmente por la percepción del diezmo que habían de pagar aquéllos"', aunque no sólo, ya que los señores también usurpaban parte de los diezmos de los cristianos viejos que correspondian a las iglesias, e, incluso, otros bienes asignados a las mismas, como los habices. Este hecho derivaba de que estos ingresos se habían convertido en una parte importante de sus rentas señoriales, dado que los lugares que habían recibido de la Corona no eran precisamente los más apropiados para obtener por otros conceptos una rentabilidad material en proporciones que colmaran sus ambiciones ${ }^{19}$. El resultado, por tanto, no podía ser otro que el inicio de un largo período de disputas y enfrentamientos entre los señores y la jerarquía eclesiástica, durante el cual iban a estar presente la violencia, el recurso a la justicia real y, en más de una ocasión, la uti-

${ }^{1}$ CABRILlaNA, N., Almeria morisca..., p. 198.

${ }^{18}$ PÉREZ BOYERO, E., Moriscos y cristianos en..., p. 292.

${ }^{19}$ Recuérdese al respecto que las mercedes de señorío otorgadas por los Reyes Católicos en Guadalupe entre el 20 y el 25 de junio de 1492, como ha señalado Pérez Boyero, "constituyen la prueba más clara del enorme poder y prestigio alcanzados por la monarquía, de su superioridad frente a los grandes magnates castellanos, que vieron desvanecerse sus ilusiones al recibir unos lugares que por su ubicación, rentas y población no satisfacian en absoluto sus aspiraciones". Ibídem, p. 63. 
lización de penas espirituales, el anatema o la excomunión, por parte de una Iglesia siempre apremiada ante la penuria de los ingresos que percibia.

Si importancia tuvieron los problemas que enfrentaron al obispo almeriense con el marqués de Villena ${ }^{29}$, entre otros señores temporales, no cabe duda que las mayores confrontaciones fueron con el Marqués de los Vélez, cuyo señorio, dentro de las tierras granadinas, ocupaba una amplia extensión de la cuenca del Almanzora y de la zona norte de Almería (Vélez Blanco, Vélez Rubio, María, Oria, Cantoria, Arboleas, Albánchez, Albox, Zurgena, Las Cuevas, Benitagla, Partaloa, Portilla); territorio tan extenso, al que había que añadir las tierras que poseía en el contiguo reino de Murcia, había propiciado un enorme poder del marqués, cuya influencia se extendía incluso a poblaciones de realengo, como sucedía en Purchena, cuyo regidor, don Juan Hurtado de Mendoza, se habia convertido en su "hombre de paja" en la localidad y, aún más, el mismo vicario, Cristóbal de Vecilla, "era criado del marqués"21.

Varias habian sido las circunstancias que originaron la excepcional formación de tan fuerte núcleo de poder en la parte nordeste del antiguo reino nazari ${ }^{22}$. Los inicios del señorio en el territorio granadino comienzan con la concesión, en julio de 1492, de, entre otros lugares, la villa de Oria al Adelantado de Murcia, don Juan Chacón, casado con doña Luisa Fajardo, poseedora del señorio de Cartagena, por sus servicios en la guerra de Granada; siete años más tarde, en 1499, don Juan "compró por 800.000 maravedís las villas de Albox, Arboleas, Benitagla y Albánchez a D. Pedro Manrique de Lara, Duque de Nájera y Conde de Treviño ${ }^{23}$. Al morir don Juan Chacón, estas cinco villas quedaron en posesión de su segunda esposa, doña Inés Manrique, en pago de su dote y gananciales, quien, no obstante, años después, en 1515, las vendió a su hijastro, Don Pedro Fajardo, volviendo así las mismas a poder de los Fajardo, que veían así acrecentados sus dominios murcianos y los almerienses que tenian desde 1503, pues en esta fecha

"obtiene las villas de Vélez Blanco y Vélez Rubio por un trueque en el que el señorío originario, Cartagena, pasa a ser jurisdicción realenga [...] y

\footnotetext{
"LÓPEZ ANDRÉS, Jesús M., «Real Patronato Eclesiástico y jurisdicción señorial: la realizaçión, por los Reyes Católicos, de la idea de "Estado Moderno" cuestianado por el Marqués de Villena en sus señorios de Tijola y Serónn, en Homenaje al Padre Tapia. Almería, 1988, pp. 357-367.

"CASTILLO FERNÁNDEZ, Javier, Macael y Laroya en la Alta Edad Moderna (1489-1650). Almeria, Instituto de Estudios Almerienses, 1998, p. 72.

${ }^{22}$ Puede consultarse una relación de buena parte de la bibliografia generada por la historia del marquesado en ANDÚJAR CASTILLO, F. y BARRIOS AGUILERA, M., «El arte de usurpar. Señores, moriscos y cristianos viejos en el marquesado de los Vélez, 1567-1568m, Sharq al-Andalts, 13 (1996), pp. 85-121.

2. LOPEZ ANDRÉS, J.M., «Erección parroquial en.... p. 498.
} 
que incluye, además, los lugares de Cuevas y Portilla -de los que ya disponía don Juan Chacón desde final de la guerra de Granada, pero que se confirmaron aquí, para que no se entendiesen perdidos en el trueque-. Cuatro años después de la permuta de Cartagena, en 1507 [...], Don Pedro Fajardo y Chacón recibe el título de Marqués de los Vélez"24

Finalmente, el marqués completa el territorio de sus dominios almerienses con la compra, el 5 de octubre de 1515, a don Diego Hurtado de Mendoza, duque del Infantado, de las villas de Cantoria y Partaloa por 2.500 .000 de maravedies ${ }^{25}$.

Hacia esa fecha el estado de las parroquias moriscas de Almería era de completa penuria y deterioro de su fábrica, ya que los 3/9 del diezmo a ellas destinadas no alcanzaban ni para pagar las rentas mínimas anuales; las razones eran los reducidos ingresos procedentes del diezmo por causa del descenso demográfico, el incumplimiento por parte de los señores de sus obligaciones patronales y "las detracciones practicadas por el deán y provisor del obispado, don Francisco Ortega, al que Rodrigo Quesada, beneficiado de Oria y Albox, acusa de haberse quedado con las rentas de las fábricas de las parroquias de toda la diócesis" ${ }^{26}$. Todo ello motivó que en 1513 se ordenase la realización de un detallado informe por parte del citado don Francisco Ortega, en nombre del obispo, y de don Pedro García de Atienza, capellán mayor de la Capilla Real de Granada, en nombre del Rey, en el que se pormenorizan, una por una, las cantidades que eran necesarias para la construcción de las iglesias ${ }^{27}$; ante ello, Fernando el Católico ordenó "librar los fondos necesarios para costear las obras de las [iglesias] que se encontraban en territorio realengo, y obligó a los señores a financiar la de sus dominios". Algunos de éstos se niegan, ya que consideraban que no era su obligación, alegando que las bulas papales dedicaban a tal fin $1 / 3$ de los diezmos ${ }^{28}$. Entre los que se opusieron estaba don Pedro Fajardo, ya enfrentado con el obispo por la distribución de los diezmos y sus obligaciones como patrono según la bula de Alejandro Vl. "Se originó, pues, una tirantez con el obispo y el marqués en la que hubo insultos e injurias por las dos partes" ${ }^{29}$, lo que dio origen al inicio de un pleito, el 14 de abril de 1526, ante la Chancilleria de Granada por negarse el segundo a pagar a la Iglesia los excusados de los lugares de su señorío. El asunto se resolvió con cierta rapidez y ambos personajes llegaron a la firma de una Concordia el 24 de septiembre de 1526. Nicolás Cabrillana sintetizó con perfección los acuerdos alcanzados con estas palabras:

${ }^{24}$ Ibidem, p. 501.

${ }^{25}$ PÉREZ BOYERO,E., Moriscos y cristianos en... p.83.

26 Ibídem, pp. 422-423.

${ }^{27}$ Puede verse en FRANCO SILVA, A., «El obispado de Almeria..., pp. 83-86.

${ }^{24}$ PÉREZ BOYERO, E., Moriscos y cristianos en..., pp. 424-425.

${ }^{24}$ FRANCO SILVA, A., "El obispado de Almería..., p. 92. 
«[...] el Marqués entregaba al Obispo mil ducados de oro en compensación de los Excusados no liquidados en años anteriores, pagados de cuatro en cuatro meses, a razón de cien ducados, hasta finalizar la paga el último día de agosto de 1527. Don Pedro Fajardo se comprometía, además, a dejar libres los excusados al Obispo, pudiendo éste elegir uno por parroquia, excepto el lugar de María que no lo pagaría "por ser lugar nuevamente poblado e metido en los límites e parroquia de Velez el Blanco". Por lo que se refiere a la renta de Habices, también pertenecientes a la Iglesia por la Bula de Erección, que el Marqués siempre había rehusado pagar, se acordó que este diera al Obispado 400 quintales de alumbres, comprometiéndose también a dejarlos, en adelante, libres para la Iglesia.

Con respecto a las Tercias, renta real de la que el Emperador Carlos V había hecho merced a la catedral de Almería para su reconstrucción, el marqués se obligó a dejar libres para el Obispo las de Vélez Blanco, Vélez Rubio, Cuevas y Portilla, pero todos los demás lugares no pagarían este tributo. El 10 de agosto de 1528 el Obispo y la mesa Capitular otorgaron a don Pedro Fajardo la carta de finiquito en la que declaran haber recibido los 1.000 ducados y los 400 quintales de alumbresy ${ }^{30}$.

Ahora bien, este concreto arreglo no había pacificado todas las tensiones presentes, ni, como veremos, fue respetado en todos sus términos. De momento, en la década de los veinte, puede decirse que las discusiones por la distribución de los diezmos y la construcción de las iglesias en los lugares de señorío permanecian prácticamente en idéntica situación a la de fines del reinado precedente, así lo pudo comprobar Carlos $\mathrm{V}$ con motivo de las deliberaciones de la Congregación de la Capilla Real de Granada (1526), asi como por el conocimiento directo que tuvo de los autos que se habian iniciado al respecto, por lo que ordenó que "los pleitos que con tal motivo pendían ante los tribunales reales se resolvieran con brevedad y las iglesias cobrasen lo que les pertenecía. Asimismo, reiteró a los señores la obligación que tenían de construir las iglesias de los lugares que se encontraban bajo su jurisdicción" ${ }^{\prime 31}$.

Los señores, no obstante, volvieron a mostrar su disposición contraria, respondiendo con evasivas y maniobras dilatorias, $\mathrm{y}$ añadieron entonces, además de la alegación anterior basada en su interpretación de las bulas alejandrinas, que la situación de las iglesias había llegado a tal grado de deterioro porque las rentas que debian haberse empleado en las mismas, se habían desviado para la construcción de la catedral de Almería, construcción en la que, a juicio de don Pedro Fajardo, en su dura línea beligerante, se había despilfarrado el dinero e, incluso,

(:) CABRILLANA, N., Aimeria morisca,.., p. 200.

"PÉREZ BOYERO, E., Moriscos y cristianos en..., pp. 427-428. 
"acusó al prelado de malversación de fondos y nepotismo" Na32. Nada extraña esta actitud, pues ese mismo año, 1526, el Obispo había planteado autos contra e1 Marqués y otros señores "sobre redificación de las Iglesias de sus estados en dho Obispado en la forma y como se hallaban obligados por la bula del Papa Alejandro Sexto por cobrar como cobraban las dos tercias partes de diezmos en los Lugares de dhos. estados ${ }^{133}$.

Mientras tanto, ante el incumplimiento de lo mandado en 1526 por Carlos V, el monarca despachó una Real Provisión, fechada en Toledo el 10 de junio de 1529 , reiterando "que los señores cumplieran lo ordenado de manera que dentro de un año estuvieran acabadas las iglesias bajo pena de secuestro de las rentas de Tercias y con ellas edificar los templos ${ }^{134}$. No obstante, nada iba a cambiar.

El pleito con don Pedro Fajardo se sentenció el 26 de julio de 1533, condenándolo la Chancillería a que cediese los 7/9 del diezmo de los cristianos viejos a la Iglesia, sentencia confirmada, ante las sucesivas apelaciones del primero, por otras sucesivas del 31 de agosto de 1536, del 1 de diciembre de 1537 y una última de 1538. Fue entonces cuando el Marqués redactó un informe demoledor contra el Obispo en el que le acusa de haber administrado las rentas de las iglesias parroquiales -entre 30.000 y 40.000 ducados- a su antojo. Y, aún más, "durante los quince años que lleva en el Obispado -sigue afirmando Fajardo- no ha nombrado nunca para Provisor a una persona de letras y ha llenado de unos «rufianes e idiotas» las parroquias de Almería, personas que no tienen méritos para que le den parte de las primicias que perciben"3s. No consiguió el Marqués revocar ni cambiar las sentencias en su contra, pero, ni los pleitos presentados, ni la clara postura real, impidieron su resistencia ni la de los demás señores, quienes utilizaron una táctica simple, la de la apelación, en el intento de agotar la paciencia y los recursos económicos de la parte contraria. El resultado solía ser llegar a una transacción, a una concordia, que contentase a ambas partes, como sucedió con Marqués y Obispo en 1540, aunque los términos de la misma fueron tan confusos -aún quedó pendiente el problema de la construcción de los templos, enlaza-

\footnotetext{
${ }^{32}$ Ibidem, p. 432.

${ }^{31}$ Archivo Real Chancillería de Granada (en adelante ARCHG), 205-5289-12.

${ }^{34}$ CABRILLANA, N., Almeria morisca..., p. 205.

${ }^{3}$ FRANCO SILVA, A., «El obispado de Almería..., p. 91. Aunque en tan demoledor informe pudiera traslucirse la profunda enemistad entre ambos personajes, mucho habría de verdad en el mismo, pues, con anterioridad, en 1528, las noticias de la desastrosa situación moral del Obispado de Almería habían llegado al Consejo de Castilla, que ordenó a don Gaspar de Ávalos, arzobispo de Granada, "girase una visita de inspección por la diócesis almeriense para averiguar personalmente los escándalos con que el Obispo don Diego de Villalán, los prebendados catedralicios y buena parte del clero parroquial tenían alarmada a la Corle de Carlos V. El Arzobispo tras la visita a nuestra comarca almeriense quedó estupefacto al comprobar que la realidad era mucho más negra que los tintes con que se narraba". CABRILLANA, N., Almeria morisca..., p. 206.
} 
do con la percepción y el reparto de los diezmos de los moriscos- que pronto volverían los problemas que se extendieron durante todo el siglo XVI, continuados por otros protagonistas - de inmediato, por don Luis Fajardo, segundo marqués de los Vélez, y por don Antonio Carrionero de Babilafuente, nuevo obispo de Almería (1558-1570)-, dándose por finalizado tan largo litigio más tarde en 1606. Sin embargo, la realidad es que ni incluso en esa fecha tan tardía la situación se debió quedar plenamente solucionada, ya que el problema resurgiría en el siglo XVIII; concretamente en 1739, el obispo de Almería, don Diego Felipe de Perea, se dirigió al Consejo de Castilla para que se volviesen a reafirmar las provisiones del siglo $\mathrm{XVI}^{36}$.

El mejor modo de comprender la actitud de los señores en toda esta situación es ver un extracto del proceder del Marqués de los Vélez tras la firma de la concordia citada de 1540 . Poco años después, en concreto, el día 20 de febrero de 1543, Bartolomé de Quesada, que tenía poder otorgado por Don Diego Hemández de Villalán, requirió al escribano de la villa de Cuevas que notificase al Marqués de los Vélez la Real Provisión que le mandaba comenzar las obras en las iglesias de su territorio, aclarándole

«que en la iglesia de las Cuevas falta enlucir la dha iglesia y tejarla y tablazón por de dentro, y en la iglesia de Cantoria falta una sacristía y tejar las dos naves de la dha iglesia de manera que se teje toda la dha iglesia, y en la iglesia de Albox tejar la dha iglesia y hacer una torre en ella, y en la iglesia de Oria falta una sacristía y una torre, y que prosiga y acabe la iglesia de Santiago de Vélez el Blanco conforme a la traza que lleva y en esto y todo lo demás cumpla y guarde la executoria segund y como en ella se contienes" ${ }^{3}$.

Tres días después, el 23 de febrero, el Marqués, "con el acatamiento debido" a la carta ejecutoria real, respondió que se le requerían "cosas imposibles de hacerse",

«A que por esto su procurador del dho marqués dará en su nombre relacion larga a los dhos señores presidente y oidores de donde emanó la dha Real provision para que vean claro que lo que el dho Bartolome Quesada pide no está en su mano poderlo hacer ni de nadie, y para esto, si necesario es, dijo el dho narques que suplicaba y suplicó de las penas que en la dha Real executoria le pone si no comienza a hacer las dhas iglesias dentro de treinta dias, que [...] no habia ni hay espacio de tiempo en treinta dias para solo trazar las dhas iglesias siendo tantas y en diversas partes,

ARCHG, 205-5289-12.

"ARCHG, 511-2252-13. 
quanto mas no estando averiguado los tamaños que han de ser las iglesias y otras cosas [...] y que esto daba por respuesta $\rangle^{38}$.

Resulta evidente que don Pedro volvía a utilizar una táctica dilatoria para no cumplir lo que se le ordenaba. Ante ello, el Obispo volvió a acudir de nuevo a la Real Chancillería y consiguió, el 10 de abril, un nuevo auto en el que se incluía una sobrecarta ordenándole al prepotente y orgulloso Fajardo cumplir la Real Provisión anterior, especificándole que el plazo de treinta días para iniciar las obras comenzaría a contar cuando el Obispo diese orden de cómo hacer las obligadas construcciones. La misma terminaba de este modo:

«os mandamos que asi hagais y cumplais so las penas contenidas e declaradas en la dicha nuestra carta executoria e solos apercebimientos que en dho auto se mandan e declaran e mas so pena de la nuestra merced e de otros doscientos mil maravedíes para la nuestra camara e fisco ${ }^{39}$.

El 23 de abril le fue notificada la sobrecarta al Marqués, indicándosele por parte del obispo Villalán las construcciones y reparaciones concretas que había de acometer de una forma más pormenorizada que en el documento anterior. El 8 de mayo, don Pedro contestó por escrito, y, persistiendo en su táctica dilatoria, expuso que tenía hecha súplica de la sentencia ante Carlos V, quien la había admitido a trámite

«e que por tanto no debe ni es obligado de justicia ni poner en obra lo que por los dbos señores presidente e oidores es mandado hasta tanto que por su majestad sea determinado en la dicha suplicacion»».

Y, además, en su afán de buscar motivos que confundieran todo, con la intención de dilatar el asunto en el tiempo, y de mostrar la malevolencia del prelado hacia su persona, añadió que el requerimiento no podía efectuarse, como en el caso anterior se había realizado, por alguien delegado por el Obispo

«porque conforme a la bula y sentencias solo su persona del prelado lo ha de hacer y no otro, y que en caso que el dho prelado lo hiciera el mismo habia de ir a los lugares y villas donde las dhas iglesias se habian de trazar y vello por vista de ojos y aun entonces la traza que el dho obispo diera no era obligado el dho señor marques a pagar por ella por ser como es muy odioso e sospechoso en todo lo que toca a su señoria y porque como es cosa notoria a los dhos señores presidente y oidores, el dho obispo tiene mala voluntad a su señoria y asi lo ha mostrado e muestra en dar favor a las personas que traen pleitos con su señoria, como es a ciertos vecinos de

\footnotetext{
${ }^{38}$ Ibídem.
}

${ }^{3}$ Ibiden. 
la ciudad de Vera que injustamente piden a su señoria y a otros sus vasallos de las villas de las Cuevas e Portilla las aguas que vienen por el rio de las Cuevas, algunas de ellas son propias de algunos de sus vasallos y otras son propias de su señoria en el uso y aprovechamiento de las cuales su señoria $\mathrm{e}$ los dhos sus vasallos cada uno en las suyas es notorio que han estado y estan mucho tiempo en quieta e pacifica posesion y el dho obispo los ba incitado e movido, y otros por su mandado a movelle los dhos pleitos $[\ldots]\rangle^{40}$.

Nos encontramos con un proceso interminable, en el que parece fuera de toda duda que don Pedro contaría con el apoyo de sus súbditos moriscos, pocos interesados en la construcción de unos templos hacia los que su devoción no los llamaba ${ }^{41}$. Persistirían, pues, los autos condenatorios de la Audiencia - 1 de agosto, 17 de agosto...-, seguidos de nuevas súplicas del Marqués, hasta enlazar con los requerimientos e, incluso, con nuevos pleitos por motivos colaterales, protagonizados por los ya citados don Antonio Carrionero, el nuevo obispo almeriense, y don Luis Fajardo, el segundo marqués de los Vélez. Y aún más allá, hasta la fecha antes citada de 1606 . Lo cierto es que puede decirse que la minoría dirigente del reino de Granada ayudó a frustrar con su actuación "una medida básica para lograr la cristianjzación de los nuevamente convertidos: la existencia de una red de iglesias parroquiales que cubriera la totalidad del territorio del antiguo reino nazan"'42.

Pero, veamos otro tipo de los enfrentamientos producidos en estos años entre la jurisdicción eclesiástica y la señorial, para ver cómo afectaba a las relaciones de poder del territorio del marquesado esta confrontación entre ambos poderes. El suceso que vamos a contemplar es un buen ejemplo de las tensiones creadas en los niveles locales. El acontecimiento a considerar tiene lugar en diciembre de 1540 en la villa de Cuevas de Almanzora. El día 29 de dicho mes se encuentra en ella don Juan de Haro, escribano real, con el fin de llevar a cabo una carta ejecutoria dada por la Real Chancillería de Granada en favor de la demanda del Obispo y cabildo de Almería; el citado escribano hace comparecer ante él

«a Juan Sanchez Gallo, clérigo beneficiado en la yglesia de la villa de Portilla, que es en el dicho marquesado, para que declarase el diezmo que debía e era obligado a pagar el año proximo pasado de quynientos e treynta e nueve años, e parescido dijo e declaró de palabra que el no haria lo que

\footnotetext{
4! Ibídem.

${ }^{41}$ Apoyo, además, lógico ante la continua protección que los moriscos recibían por parte del Marqués, lo que se manifestaría en que "en el momento del levantamiento de los moriscos en 1568-70, los del marquesado, no se alzaron en armas". ALCAINA PÉREZ, Pelayo, «La Inquisición en el Marquesado de los Vélez. La visita de 1561 ', Revista Velezana, 7 (1988), p. 26.

${ }^{42}$ PÉREZ BOYERO, E., «La construcción de las..., p. 81.
} 
yo el dicho executor le mandaba a cerca de que pagase el dicho diezmo e lo declarase, e que no era obligado a parescer ante mí e que yo fuese a la dicha villa de Portilla, por manera que en desacato de la dicha provisión de sus majestades que es muy notoria en dicho marquesado, dijo muchas palabras aceleradamente en mi presencia e de otras muchas personas a la puerta del mesón de la villa de las Cuevas, y menospreció e desacató dicha provisión»"

Ante la situación, el escribano requiere a don Juan Gutiérrez, vicario general del obispado de Almería, quien también estaba presente en el acto, para que le de facultad con el fin de prender al citado clérigo beneficiado; de inmediato se la concede, haciendo expresamente constar que le da licencia "para que pudiese prender e apremiar al dicho Juan Sanchez Gallo, para que se hiciese e cumpliese lo que con justicia el dicho Juez le mandase en execucion de la dicha provision e le pudiese apremiar a ello como si fuese lego". El resultado fue la prisión del clérigo en la cárcel de Cuevas, aunque la misma no se hizo sin impedimento, ya que Juan de la Cadena, escribano público de la villa, por tanto, hombre del Marqués, intentó con cierta violencia impedirlo, llegando incluso a clamar "¡aquí los del marqués!", a pesar de que el don Juan de Haro había pedido favor y ayuda "a la Justicia del Rey".

Al día siguiente, 30 de diciembre, el caso presentó una vertiente nueva, pues don Juan de Haro recibió un mandamiento firmado por el vicario general del obispado, don Juan Gutiérrez, en el que le requería, bajo pena de excomunión, que desistiese en la causa que había emprendido contra le beneficiado de Portilla y la remitiese ante la autoridad eclesiástica, mandato que fue obedecido por el escribano real, aunque previamente, el mismo día 30 por la tarde, el clérigo cuestionado "declaró con juramento el diezmo".

No quedó aquí el asunto, ya que don Juan de Haro pretendió que el citado don Juan de la Cadena, escribano público de Cuevas de Almanzora que había intentado poner resistencia física a la justicia real, fuese debidamente castigado, por lo que se acercó a la vecina ciudad de Vera

«a notificar e notifiqué [expresa don Juan de Haro] a Diego Montiel receptor de la dha Real Audiencia que a la sazón estaba en la dha ciudad, e a Luis de Narvaez alcalde mayor della, que asistiesen conmigo a tomar $\mathrm{e}$ recibir la informacion susodicha contra el dho Juan de la cadena para que a sus majestades e a los dhos señores presidente e oidores de la dha Real Audiencia constase de lo susodicho e proveyesen en ello lo que fuese justos ${ }^{44}$.

${ }^{43}$ ARCHG, 513-2529-9. 
Contiene después el expediente las declaraciones de los testigos presentados por el escribano real, quienes ratificaron la actuación violenta de Juan de la Cadena manifestándose de modo claro y público contra la justicia real. No se conserva en la documentación resolución o sentencia alguna. El suceso, en principio no de gran trascendencia, dada la entidad de los personajes en litigio y la cuantía de las rentas que se exigían, es, sin embargo, representativo de lo que podía llevar consigo un conflicto de este tipo. En primer lugar encontramos en él la intervención de la justicia real como consecuencia de un pleito mantenido entre el Obispo almeriense y el Marqués de los Vélez, basada en la resolución favorable para el primero de una sentencia de la Audiencia granadina; el acontecimiento origina, como consecuencia, un enfrentamiento entre la justicia real y la del Marqués; pero, además, y de un modo en el que se percibe con nitidez las complejas relaciones entre la variedad de jurisdicciones existentes durante el Antiguo Régimen, también se produce un conato de fricción entre la jurisdicción eclesiástica y la real -reclamación del clérigo prisionero en una cárcel real por parte de la autoridad episcopal-, a pesar de que esta última había actuado en apoyo de la primera. Un ejemplo más, por tanto, que corrobora la opinión de considerar a aquella sociedad como una "sociedad de pleiteantes"; no era una simple inclinación de nuestros antepasados por acudir a los tribunales, el hecho era más profundo, se trataba de que la propia estructura política -también la socio-económica- en que se hallaban insertados propiciaba la proliferación de situaciones de este tipo en las que el conflicto jurisdiccional era el ingrediente inevitable, conflicto que no siempre los tribunales reales podían resolver en un plazo de tiempo prudencial y de forma satisfactoria, lo que propiciaba, sin duda, la existencia de tensiones en aquella sociedad en la que aparentemente se vivía sin la presencia de un malestar social capaz de originar movimientos airados de protesta. La realidad, por el contrario, aunque muchas veces oculta o disfrazada, era bien diferente.

\footnotetext{
${ }^{44}$ Ibídem.
} 